Western University

Scholarship@Western

Undergraduate Honors Theses

Psychology

Winter 4-30-2015

\title{
Features of Classroom Instruction and Self-- -Regulation In the Elementary Years
}

Devon Trower

King's University College, dtrower@uwo.ca

Follow this and additional works at: https://ir.lib.uwo.ca/psychK_uht

Part of the Psychology Commons

\section{Recommended Citation}

Trower, Devon, "Features of Classroom Instruction and Self--Regulation In the Elementary Years" (2015). Undergraduate Honors Theses. 26.

https://ir.lib.uwo.ca/psychK_uht/26

This Dissertation/Thesis is brought to you for free and open access by the Psychology at Scholarship@Western. It has been accepted for inclusion in Undergraduate Honors Theses by an authorized administrator of Scholarship@Western. For more information, please contact tadam@uwo.ca, 
Features of Classroom Instruction and Self-Regulation In the Elementary Years

By

Devon Trower

Honors Thesis

Department of Psychology

King's University College at Western University

London, Canada

April 2015

Thesis Advisor: Lynda Hutchinson, Ph. D. 


\begin{abstract}
The present study is part of a larger project examining relationships between children's selfregulation (SR), features of instruction, and peer relationships. This study utilized a mixedmethod research design to investigate children's SR in two elementary school classrooms $(N=$ 33 children; 18 males; Mean Age $=8.56$ years). Specifically, four questions were posed in the present study: Does SR predict academic achievement? What is the effect of the demographic variable sex on SR? To what extent are the features of classroom instruction present in classrooms? How do features of classroom instruction provide opportunities for children's engagement in ER and SRL? Teachers provided ratings of their students' SR using the 9-item Self-Regulation In School Inventory. Features of instruction were examined using the Classroom Observation Instrument. Results of a multiple regression analysis revealed that SR was a statistically significant predictor of academic achievement, $F(2,30)=7.89, p=.002$ R-squared $=$ .35 , Cohen's $f=0.53$, indicating a medium effect size. Findings demonstrated that boys obtained statistically significantly lower ratings of SR from teachers compared to girls, $F(1,31)$ $=12.36, p=.001, \eta_{p}{ }^{2}=0.29$, corresponding to a small effect size. Also, the results of this study indicated that the features of classroom instruction provided opportunities for children's SR in classrooms, but there were qualitative differences in teachers' implementation of the features. Findings highlight the need to provide pre-service and in-service teachers with education illuminating the importance of teaching towards SR in classrooms.
\end{abstract}




\section{Dedication}

I dedicate this thesis to my wonderful parents, Brad and Karen. Thank you for all of your love and support. 


\section{Acknowledgements}

I would like to acknowledge Dr. Lynda Hutchinson, for being my mentor and guide through this experience. I could not have asked for a more patient and knowledgeable advisor. As well, thank you to my dear family and friends. You are all appreciated. 
Features of Classroom Instruction and Self-Regulation In the Elementary Years

Self-regulation (SR) refers to how individuals control thoughts and actions to respond to environmental stimuli (Zimmerman \& Schunk, 2011). Research has demonstrated that SR involves basic executive processes (i.e., behavioral inhibition/behavioral control, working memory, and effortful control; Diamond \& Lee, 2011) and the application of higher order cognitive processes such as: metacognition, motivation, and strategic action (Eisenberg \& Spinrad, 2004; Perry, Thauberger, \& Hutchinson, 2010; Hutchinson, 2013; Perry \& Winne, 2006). Metacognition is how individuals appraise and monitor situations. Individuals are metacogntive when they consider strategies to manage task demands. Motivation is reflected in how individuals approach new and challenging tasks. Individuals demonstrate motivation when they consider errors as opportunities to learn and improve. Strategic action refers to the behavioral enactment of metacognition and motivation. Individuals are strategic when they assess that help is needed with a task, and ask to collaborate with peers to solve the task. Hutchinson (2013) has indicated that metacognition, motivation, and strategic action are central processes to conceptually distinct aspects of SR studied in developmental and educational psychology.

\section{Emotional Regulation in Developmental Psychology}

Developmental psychologists have studied SR as executive functioning (e.g., effortful control), and also as Emotional Regulation (ER). ER is described as individuals' management of affect, to thrive in a given context (Sokol, Grouzet, \& Mueller, 2013). Consistent with Hutchinson (2013) ER is defined as individuals' regulation of affect to manage classroom learning using metacognition, motivation, and strategic action. In a classroom environment, 
metacognition for ER is observed when a child identifies and effectively communicates his/her affective internal states such as excitement, anger, or sadness. Children demonstrate motivation for regulating affect when they maintain a positive outlook about learning, even when a task is completed unsuccessfully. Children engage in strategic action for ER when they adopt tactics to cope with negative affect to support their engagement in learning (e.g. seeking help on a difficult task instead of getting frustrated; Hutchinson, 2013; Perry, Thauberger, \& Hutchinson, 2010).

Children's ER has been recognized as a precursor to children's social and academic success. That is, children who demonstrate ER during preschool have social, behavioral, and academic advantages in school (Eisenberg \& Spinrad, 2004). For example, in their longitudinal study Eisenberg, Fabes, Murphy, Maszk, Smith, \& Karbon (1995), examined 82 children's ER (44 boys) in kindergarten and again in grade 2 . They observed that children with high teacherreported ER and low emotionality in kindergarten were more likely to engage in adaptive and prosocial behaviours in grade 2 .

More recently, Fuhs, Nesbitt, Farran, \& Dong (2014) observed four year-olds ( $N=562$ ) three times over during an 18-month period. Researchers measured children's ER (vocal and motor control, inhibitory control, working memory, attention flexibility), IQ ( 5 subtests measuring math, language, and literacy from the Woodcock-Johnson III), and academic achievement (math, literacy, and language achievement scores) during each wave of data collection. Results demonstrated that statistically significant and positive relationships were observed between children's engagement in ER and IQ, and ER and achievement. Taken 
together, these results demonstrate that children's development of and engagement in ER is critical to their learning in school.

Some research has indicated that demographic variables such as sex, may be a factor in children's development of and engagement in ER (Diamond \& Lee, 2011; Hutchinson, 2013; Rudasill \& Rimm-Kauffman, 2009; Konald \& Pianta, 2005). For example, Rudasill and RimmKaufman (2009) gathered observational data about 819 grade one students (413 boys, 406 girls) to examine the relationship between child temperament and teacher- child interactions. Results of this study indicated that teachers rated boys statistically significantly lower on ER compared to girls, and teachers in this study reported having more conflict-laden relationships with boys. These findings are concerning, because poor relationships in the early school years have portend unfavorable developmental and educational outcomes for children (e.g., risk of peer rejection, internalizing/externalizing symptoms). The present study examines teachers' perceptions of children's SR, and the potential effect the demographic variable sex on teachers' ratings of children's SR.

A review of the literature indicates that the majority of research on ER has been conducted with preschool children and children who are "at risk" for psychological disorders (Barnes, Vogel, Beck, Schoenfeld, \& Owen, 2008; DeWall, Baumeister, Stillman, \& Gailliot, 2007; Surman, Biederman, Spencer, Yorks, Miller, Petty, \& Faraone, 2011). Children "at risk" are those who are exposed to chronic adversities (e.g., low socioeconomic status, low parental education) that are likely to impact their day-to-day functioning (Martin, Gins, Brackett, Malmberg, \& Hall, 2013) rather than children who are typically developing but who navigate the day-to-day challenges of learning in school (e.g., not doing well on a test). There is a need for research to 
focus on understanding how typically developing children's ER develops during the early elementary grades. The purpose of this study is to examine how typically developing children's ER and SRL are supported through features of instruction.

\section{Self-Regulated Learning in Educational Psychology}

Educational psychologists study SR applied to learning or self-regulated learning (SRL), independent and effective patterns of learning requiring metacognition, motivation for learning, and strategic action (Perry, 2013; Winne \& Perry, 2000; Zimmerman \& Schunk, 2011). Children exhibit metacognition when they appraise their strengths and weaknesses as learners, when they set realistic expectations for their learning, and when they choose an efficient and effective strategy that supports learning (Perry, Turner, \& Meyer, 2006). Motivation for learning involves self-efficacy, attributions and goal orientations (Hutchinson \& Perry, 2014, under review; Perry, 2013; Perry, Thauberger, \& Hutchinson, 2010). Children demonstrate motivation for learning when they pursue goals to gain a deeper understanding of concepts, or when they choose to complete challenging academic tasks. Strategic action is reflected in learners' integration of metacognition and motivation for learning (Hutchinson, 2013). Learners engage in strategic action when they seek help from a peer or teacher to complete a task.

SRL has been associated with positive learning outcomes for young children. These include deep rather than surface level cognitive processing, and high levels of academic achievement (Elliot- Faust \& Pressley, 1986; Merritt, Wanless, Rimm-Kaufman, Cameron, \& Peugh, 2012; Perry, Thauberger, \& Hutchinson, 2010; Perry \& Vandekamp, 2000; Zimmerman \& Martinez Pons, 1986). 
For example, Perry (1998) employed a case study research design to examine opportunities for children's SRL in five grade 2 and 3 elementary school classrooms to examine: (a) The features of instruction and opportunities for SRL present during language and literacy activities and (b) children's perceptions of the features of instruction and opportunities for SRL present in classrooms. Results indicated that classrooms that supported children's SRL provided opportunities to make meaningful choices and control challenge. These opportunities supported children's engagement in metacognition for SRL (e.g., completing self-evaluations of learning, utilizing self-monitoring strategies). For example, one low achieving student from a high-SR classroom, reported that she "was learning "harder words" and that "the more she used them, the easier ... the less [she had] to check."(Perry, 1998, p. 723).

In classrooms where there was less support for SRL, the classroom context provided fewer opportunities for children to engage in self-evaluation, receive instrumental forms of support for their learning, or to apply meaningful cognitive strategies. According to Perry (1998), children in these classrooms appeared more concerned about external evaluations and grades, and were observed engaging in defensive and self-handicapping learning practices (e.g., avoiding difficult tasks for fear of failing).

SRL is contrasted with patterns of learning that are characterized as defensive or selfhandicapping (Paris \& Paris, 2001; Turner \& Paris, 1995). Children who engage in these patterns of learning tend to experience negative educational outcomes such as: lack of motivation and less desire to persevere in the face of a challenging task (Turner \& Paris, 1995). For example, Heyman and Dweck (1998) gathered interview data from 202 second and third grade children. Researchers asked children questions to investigate attributions of success (trait 
attribution vs. process attribution), and how they influenced children's perceptions of their academic and social performance. Researchers separated the sample into two groups according to their attribution beliefs. Children who displayed success trait stability (i.e., they attributed success to characteristics ingrained in the individual, e.g., "she is just smarter") were more likely to attribute a lack of success on a task to ingrained characteristics (e.g., I am good, stupid, mean). Conversely, children whom were characterized as having more process attribution were more likely to rationalize success as an outcome of strategy (e.g., "she gets help when she needs it").

Findings from this study indicated that the children in the trait attribution group were less likely to employ metacognitive strategies to suggest effective solutions to tasks (Heyman \& Dweck, 1998). Children in this group were also more likely to report that their intelligence was fixed (i.e. if they were "bad" at math, they would always be bad). Results of this study demonstrate that these internal attribution models are prevalent in young children and when children have trait performance attributes, they are less effective at engaging in adaptive learning strategies and are more likely to engage in negative self-evaluations.

To date, the majority of research about SRL has involved learners in high school and university rather than young children. However, studies indicate that children's beliefs about are shaped by their early school experiences (Heyman \& Dweck, 1998; Perry, 1998; Turner \& Paris, 1995). Therefore understanding how children's ER and SRL are related to their classroom learning during the elementary years is warranted. The present study examines how children's ER and SRL can be supported through features of classroom instruction.

\section{Features of Instruction}


Research is accumulating evidence indicating that features of classroom instruction can support children's learning and development of ER and SRL in school (Hutchinson, 2013; Perry 1998; Perry \& Winne, 2006). Classrooms that provide opportunities for children's development of SR are characterized as democratic and autonomy supportive (Perry, 1998). Classrooms that encourage children to reflect on their learning, communicate effectively, and engage in discussions about their work and learning (Heyman and Dweck, 1998; Hutchinson 2013). Researchers have identified eight features of instruction that provide opportunities for children's development of and engagement in ER and SRL (Hutchinson, 2013; Perry, 1998). These include: complex tasks, choices, control over challenge, self-evaluation, teacher and peer support, non-threatening evaluations and a community of learners. These eight features of classroom instruction are being examined in the present study and are discussed in turn, below.

Complex tasks. Complex tasks are the academic activities that take place inside a classroom when children are learning (Hutchinson 2013; Perry, 1998). Tasks that are complex by design have five main characteristics: they usually involve multiple learning goals, integrate subject matter, require sustained learning (over time), involve co-ordination of multiple processes (e.g., planning work and synthesizing information), and typically result in a number of learning products (Hutchinson, 2013; Samarapungavan, Mantzicopoulos, and Patrick, 2007). An example of a complex task would be a research project completed over a period of days or weeks. The project could combine subject content such as scientific research strategies, literacy skills, as well as synthesizing and organizing information; with each phase requiring the student learn to create short-term task goals that contributed to the successful completion of the larger project goals. 
Samarapungavan, Mantzicopoulos, and Patrick (2007) developed a complex task for 65 kindergarten students using an inquiry learning framework. The program was eight weeks, allowing for prolonged exploration of the topic. The program required children to observe butterflies, record their observation in notebooks (drawing, writing, invented communication), create their own questions, and draw conclusions about their collected data. The researchers concluded that when kindergarten students engaged in this task, they had more opportunities to engage in SRL (e.g. motivation of explore their individual questions, synthesizing information, and evaluating their work throughout the process).

Choice and control over challenge. Choice refers to meaningful opportunities for children to manage their work and learning (Perry, 1998). Often, opportunities for children to make meaningful choices also provides opportunities for learners to control challenge (Corno, 2001). Teachers can provide meaningful opportunities for children to control challenge when they allow children to make decisions about the topic of research project or the level and topic of book they read.

Choices and control over challenge have been implicated in children's SRL. For example, Stefanou et al. (2004) conducted naturalistic observations in grades 5 and 6 classrooms using audio recordings from 84 math classes. Findings demonstrated that when children were given the opportunity to make choices about the organization (e.g., work in groups versus partners), procedure (e.g., presenting information using slideshow, video, song) and cognition (e.g., use of multiple solution strategies) involved in a task, children were able to make pertinent choices about their learning. 
Self-evaluation. Self-evaluation refers to opportunities for children to reflect on their work and learning (Corno, 2001). Children may have opportunities to engage in self-evaluation when they are asked to use a rubric to judge whether they have met expectations on a learning task or when they are asked to consider how their behavior impacts another child's learning. Children can use self-evaluation to review strategies, make improvements to work, assess overall success; using all three to better adapt to specific task requirements (Hutchinson, 2013). In fact, self-evaluation practices have been linked to children's ER and SRL while learning (Perry, 1998; Hutchinson, 2013). For example, Perry and Vandekamp (2000) collaborated with five teachers to facilitate meaningful opportunities for ER and SRL over three years. In year one, the preliminary round of data collection indicated that children felt it was difficult to receive criticisms of their work, and view them as a positive learning opportunity. After three years, in classrooms with high levels of opportunities for ER and SRL, researchers observed that $85 \%$ of students in classrooms indicated that they felt it that when they had opportunities to review their work, it was improved. Additionally, that they took more pride in the finished product once they had reviewed it. Results of this study indicate that children's ER and SRL can be supported through participation in self-evaluations of learning.

Teacher and peer support. Teacher and peer support refer to opportunities for children to seek instrumental forms of scaffolding and support to manage their learning in classrooms (Corno, 2001). Teacher and peer support reflect Vygotskian and neo-Vygotskian models of learning, which reflect emphasis of interaction between the learner and others in the environment (Thomas, 2005). Vygotsky advocated that a child could be assisted in the transition from their current skill level, to a higher level through co-regulation (interactions 
among individual, social, and cultural sources of influence that together work in tandem to guide learning; McCaslin, 2009) from a more experienced learner (e.g., a teacher or peer). For example, when a math task becomes too frustrating or difficult, the student is encouraged to make contact with other individuals in the classroom (most often a teacher or peers), to successfully manage task demands. Hutchinson (2013) has indicated that teacher and peer support are essential features for supporting children's development of and engagement in ER and SRL at school.

Non-threatening evaluations. Non-threatening evaluations focus on the individual's processes of learning and personal growth, rather than emphasizing grades or social comparisons (Butler 1990; e.g., to peers). An example of a non-threatening evaluation may include journals were children keep track of their own learning process, prompting selfreflection (Hutchinson, 2013).

Community of learners. Communities of learners refer to a culture of classroom learning that operates from shared knowledge base and has a socially shared set of values, norms, and expectations (Collins, Brown, \& Newman, 1989). Communities of learners have four characteristics: they couple individual responsibility with group support, encourage children to share ideas and strategies, make allowances for individual differences and support relationships between teachers and children (Battistich, Solomon, Watson, \& Schaps, 1996; Brown \& Campione, 1994).

\section{The Current Study}

The present study examined how two aspects of SR - ER and SRL were supported through eight features of classroom instruction (complex tasks, choice and control over 
challenge, self- evaluation, teacher and peer support, non-threatening evaluations, and communities of learners). Research has demonstrated that the inclusion of these features of instruction provides opportunities for children's development of and engagement in ER and SRL in school. The majority of research on ER involved pre-school students whereas research on SRL has typically involved older students in college or university (Hutchinson, 2013). There is a need for research that examines how ER and SRL are implicated in children's learning during the early elementary school years. Therefore, the present study is employing a mixed-method research design to examine how ER and SRL are promoted and support in classroom contexts. This study has been employed to answer four research questions:

1. Does SR predict academic achievement?

2. What is the effect of the demographic variables sex on SR?

3. To what extent are opportunities for SR present in classrooms?

4. How are features of classroom contexts related to children's engagement in ER and SRL?

\section{Method}

\section{Design}

This study utilized a mixed method research design to address four research questions.

\section{Participants}

Participants were two elementary school teachers ( 1 male) and their students $(N=33$; 18 boys) from two split grade classrooms (i.e., $2 / 3 \& 3 / 4$ ). The average age of participating children was 8.56 years old $(S D=0.89$ years). Children were attending school in a suburban Catholic school district outside of London, Canada. Teachers provided ratings of classroom socioeconomic status (SES) and indicated that the children in their classrooms were from a low- 
middle SES background (see Table 1 for classroom demographics). The school district involved in this study serves families from a range of socio-economic, linguistic, and cultural groups.

\section{Measures}

Self-Regulation In School Inventory. For this study, the nine-item version of the teacher-report tool, the Self-Regulation In School Inventory (SRISI; Hutchinson \& Perry, under review) was employed to provide indirect assessment of children's academic achievement and behaviors associated with SR - ER, SRL, and Socially Responsible Self-Regulation (see Appendix A).

Academic achievement. One item provided an assessment of children's academic achievement ("Overall what is the child's achievement level in terms of provincial expectations?"). Teachers used a 7-point Likert Scale to provide achievement ratings with anchors at four scale points: Achievement Level 1 (1), Achievement Level 2 (3), Achievement Level 3 (5), and Achievement Level 4 (7). The rating scale for the achievement items corresponds with the Ontario Ministry of Education Grading Standards.

Emotional regulation. Two items measured student's ER - students' regulation of affect. ER ("Is able to talk about feelings or express emotions").

Self-regulated learning. Three questions measured SRL - adaptive and independent approaches to learning (e.g., "Is willing to try challenging tasks").

Socially Responsible Self-Regulation. Three questions on the SRISI measured a construct of SR called Socially Responsible Self -Regulation (SRSR; e.g., Recognizes how much support peers need for learning"). SRSR manifests in the way that a child is able to collaborate and be cooperative in the classroom. 
Teachers responded to the SR items using a seven-point Likert scale with endpoints ranging from 1 (never true) to 7 (always true). Hutchinson and Perry (under review) report that the SRISI exhibits good psychometric properties. Specifically, they have found that items adhere to a two factor model of SR with a Root Mean Square Error of Approximation (RMSEA) statistic $=0.07$, indicating acceptable model fit (Vandenberg and Lance, 2000). They have also reported Cronbach's alpha values of internal consistency for total scores of SR ranging from .87 to .97. In the present study, Cronbach's alpha for the SRISI was computed at .96, indicating a good lower bound estimate of reliability. Teachers completed one set of SRISI items for each participating child. An average total score of children's SR was computed by aggregating item scores, and dividing by the number of items.

Classroom Observation Instrument. The Classroom Observation Instrument (Perry, 1998; Appendix B) was employed in this study to provide a written description of the events and activities that transpired in classroom contexts (Perry, 1998; Perry et al., 2006; Perry \& VandeKamp, 2000). The classroom observation instrument contains three sections. The first section provides space for the researcher to indicate the date and time of the observation, subject being observed, teacher being observed, and the grade of the classroom. The second section contains space for the researcher to provide a written summary of the events and activities that transpire during classroom observations, including verbatim speech between a teacher and students. The third section is a checklist with a table of the conceptual categories/features of instruction that are known to provide opportunities for SR (i.e., complex tasks, choices, control over challenge, self-evaluation, teacher support, peer support, nonthreatening evaluations, community of learners). Column one provides a list of the conceptual 
category, and column two provides a description of how that category may manifest in classrooms during learning. It is important to recognize that the conceptual categories examined in this study are not mutually exclusive - the presence of one category may indicate the presence of another category (e.g., providing children with opportunities to make meaningful choices can also provide opportunities for children to control challenge). As data were analyzed, the conceptual categories were revisited to examine how they reflected the categories present in classroom contexts and in the literature (Strauss \& Corbin, 1997).

Checking classroom observations for features of instruction. After a classroom observation was conducted, the classroom observation checklist in Section 3 of the Classroom Observation Instrument (Appendix B) was used to rate the extent to which features of instruction were present in classrooms. The first column of the checklist displays eight features of instruction known to provide opportunities for children's SR. The second column provides space for the researcher to conduct a qualitative appraisal of the presence of the conceptual category/feature in the classroom. The third column provides a place for a researcher to judge the implementation of the feature during the lesson/task observed. Each conceptual category/feature of instruction received a quantitative rating indicating the presence and extent to which they provided opportunities for SR.

Inter-rater reliability for classroom observations. My supervisor and I conducted a full-day of observations in participating classrooms. After we were finished the observations, we used the section 3 of the classroom observation instrument to independently judge the presence and implementation of the features of classroom contexts in the lessons we observed. We discussed our judgments and resolved any discrepancies until consensus was reached. 
Coding of the running records. The running records from the tasks observed in each classroom were coded using the Classroom Observation Instrument coding protocol to examine how the features of instruction provided opportunities for SR during the full day of observations. A total of three tasks were observed in each classroom. First, the use of each feature of instruction was rated for its presence ("yes observed / no, not observed"). Then, each feature was qualitatively judged on the extent to which the feature was implemented to provide opportunities for children's SR. The shading provided in Table 4 reflects the extent to which each of the eight features of instruction were implemented during each task, with pink (not implemented), green (somewhat implemented), and grey (fully implemented).

Demographic Form. A demographic form was used to gather information about the participating classrooms (See Appendix C). The form included space regarding total, number of children in the class, classroom SES, total number of boys and girls, number of children who are from visible minority backgrounds, and number of children who speak English as a second language.

\section{Procedures}

Ethics approval, participant recruitment, and informed consent. The present study was part of a larger project examining relationships between children's SR, features of instruction, and peer relationships. The larger project and this study were approved by the King's University College at Western University review board and the participating school district. The school district's approval indicated that the study and measures met their internal guidelines for the treatment of young children as research participants.

In the summer of 2014, my supervisor approached the school district to inquire about 
the possibility of conducting research on SR there. In February, 2015, after the school district approved the study, my supervisor contacted principals from two schools to explain the study and whether teachers and their students from their school may be interested in enrolling in it. The two school principals distributed the teacher consent forms to their teaching staff. Teachers enrolled in the study by contacting my supervisor. After consent forms were signed by teachers, my supervisor and I attended participating teachers' classrooms to distribute a class set of parent consent forms. The parent consent forms were taken home by children. To increase participation rates, children who returned their consent forms were given a "fancy school pencil".

Classroom observation training. I was trained by my supervisor to conduct classroom observations. I was given instruction on what is expected of observers in the classroom (e.g.,I was educated on what behaviours to look for, how to record observations effectively, and how to code results).

Classroom observations. During February 2015, I conducted a full-day of classroom observations (approximately 4 hours) in participating teachers' classrooms using the Classroom Observation Instrument. I observed tasks and activities that transpired in classrooms across different subject areas rather than focusing on one subject area multiple times. The beginning and end of each classroom observation was marked on the Classroom Observation Instrument. Consent forms for the electronic questionnaire data were collected on the same day as the classroom observations. When I conducted a classroom observation, I positioned myself in the classroom to see and hear what was going on in without interfering with the activities taking place. I completed a running record - a written description that summarized the events that 
took place while I was there, including samples of speech between teachers and children, and children and their peers. After I completed my observations, I reviewed my notes and annotated my records to ensure that I had a complete and accurate recording of the classroom activities. Then, I used the checklist in Section 3 of the Classroom Observation Instrument to code my observation for the extent to which the features of instruction were present in classrooms and provided opportunities for children's engagement in SR.

Qualtrics Survey Tool. In my study, I employed Qualtrics Survey Tool to distribute the Self-Regulation In School Inventory (SRISI; Hutchinson \& Perry, under review) to participating teachers. Qualtrics Survey Tool is a software program used for creating and distributing electronic questionnaires using the Internet. The software allows for researchers to create new questionnaire items, or upload items from existing surveys and to customize the response scale used for each question.

Administration of the SRISI. In March of 2015, teachers were asked to log on to "Qualtrics Survey Tool" to complete the SRISI. Teachers completed one set of SRISI items for each participating child in their classroom.

\section{Results}

This study utilized quantitative and qualitative data to investigate SR and features of classroom instruction. Data gathered from the SRISI and classroom observation instrument were employed to address the four research questions posed in this study. The results that appear below are presented in order of the research questions posed at the outset of this study.

Does Self-Regulation (SR) Predict Academic Achievement? 
Table 2 displays the descriptive statistics for the SR and academic achievement variables for the total sample and for participating classrooms. Tyler's rating of his students' SR ( $M=$ $4.40, S D=1.26)$ and academic achievement $(M=4.65, S D=1.32)$ were not statistically significantly different from Tori's ratings of her students' SR $(M=4.53, S D=1.61)$ and academic achievement $(M=4.31, S D=1.58)$. Therefore, data from both classrooms were combined to compute a multiple regression analysis and examine whether SR predicted academic achievement. Specifically, SR was employed as the predictor variable and achievement was the criterion variable, while holding the statistical effects of the demographic variable sex, constant.

Results demonstrated that SR was a statistically significant and positive predictor of academic achievement, $F(2,30)=7.89, p=.002$ R-squared $=.35$ (see Table 3 ), corresponding to a Cohen's $f=0.53$, indicating a medium effect size.

\section{Does the Demographic Variable Sex have an Effect on SR?}

A one-way ANOVA was employed to examine the effect of sex on SR. Results demonstrated a statistically significant effect of sex on the SR variable, $F(1,31)=12.36, p=$ $.001, \eta_{p}{ }^{2}=0.29$, corresponding to a small effect size. Results indicated that teachers provided statistically significantly higher ratings of $S R$ to girls $(M=5.28, S D=1.00)$ compared to boys $(M=$ 3.78, $S D=1.37)$.

\section{To what extent are the features of classroom instruction present in classrooms?}

The running records obtained from the classroom observations were analyzed to investigate the extent that features of instruction were present in classrooms during a full day of observations. The purpose of the classroom observations were to understand how Tori and 
Tyler provided opportunities for children's SR in their classroom lessons. Table 4 lists the tasks/subjects that were observed and whether (a) the features of classroom instruction were present in each lesson and (b) the extent to which the feature was implemented in providing meaningful opportunities for SR during classroom tasks.

Table 4 indicates that qualitative differences were observed in the presence and implementation of the eight features of instruction in Tyler and Tori's classrooms. In Tyler's classroom, the implementation of complex tasks was observed across all three tasks. He consistently allowed for children to make choices about their learning, and in doing so, control the challenge of the task. Teacher and peer support were implemented in Tyler's classroom across the three lessons. There was limited evidence that children had opportunities to engage in self- evaluation and non-threatening evaluations. In Tori's classroom, opportunities for children to obtain instrumental forms of teacher and peer support were consistently limited across the lessons I observed. Also, in Tori's classroom the remaining six features of instruction (i.e., complex tasks, choice, control over challenge, self-evaluation, non-threatening evaluations, and a community of learners) were not present and implemented during lessons on the day of my observation.

\section{How Do Features of Instruction Provide Opportunities for SR?}

To examine how features of instruction provided opportunities for SR in classrooms, I selected one lesson from each classroom to contrast how the eight features of classroom instruction were implemented.

Tyler's writing task. A full-day of classroom observations were conducted in Tyler's grade 3/4 classroom, in February 2015. A total of three lessons were observed on this date, for 
approximately 3 hours. The decision was made to examine a writing activity that the class was engaged in, Overall, eight features of instruction were observed in Tyler's writing task; including complex tasks, choice, control over challenge, self, evaluation, peer support, teacher support, non-threatening evaluations, and community of learners. Figure 1 displays the degree to which the features of classroom instruction were implemented during the writing task in Tyler's classroom.

The goal of the writing task was to afford children opportunities to practice (a) following instructions (b) creating a chart as an outline for writing their persuasive paragraphs, (c) generating an argument in support of or against wearing uniforms based on class discussions, (d) developing collaborative skills, and (e) working on their persuasive writing skills.

The writing task was deemed to be complex by design. The task was built on a larger unit of writing persuasion (the class had previously held a debate which focused on making persuasive arguments). Students were introduced to the topic of uniforms in a class discussion. Then, they were given instructions to generate their own chart of pros and cons (for wearing uniforms) and were supported by Tyler to use the chart as a guide for their persuasive argument. The presence of these steps provided evidence that the task was composed of several phases and resulted in multiple products (discussion, charts, and paragraphs), which are characteristic of complex tasks.

On the day of the observation, children were gathered on the carpet to begin a discussion about the pros-and-cons of uniforms. Tyler began the lesson by playing a video about uniforms; then defined the difference between a pro and a con to the children. Then, children were given the choice to read a portion of an article about uniforms to the class, on a 
voluntary basis. Several children raised their hands to read a paragraph of the article. After a student read the first paragraph, Tyler asked the children, "What are some jobs that require uniforms"? In doing so, he provided children with the opportunities to engage in metacognition for SR so they could consider how their writing topic was linked to the jobs their family members and other community figures held.

The children continued through the paragraphs and after each one was read by a volunteer, Tyler provided support by further explaining the paragraph to the children. One child remarked that his cousin didn't have to wear a uniform, and this fueled a class discussion. After a few moments of discussion, Tyler told the children that it was time for gym. The children left the classroom, and returned approximately thirty minutes later.

After the activity session in the gym, Tyler built on the task by instructing the children to take the knowledge that they had built in that morning's discussion of uniforms versus nonuniforms and pros and cons to generate a table of how they felt about uniforms. Tyler informed the children that once they had completed their chart, they could use the list of pros and cons to construct a persuasive paragraph to explain what position they would take on the topic of uniforms. Here, Tyler provided instrumental support that could support children's motivation and strategic action for SR. Tyler explained the project and how they could use their previous work to support them with their persuasive writing paragraphs saying "If you decide to write in support of uniforms, you should use your advantages side [of your chart ".

As the children completed their charts, they approached Tyler for evaluation. Tyler deemed that the child needed to elaborate on his argument, so he said to the child "Okay, so you like your own clothes, what else can you write about that"? In this instance, children had 
the opportunity to receive non-threatening evaluative feedback to revise and edit their writing. By providing this feature of instruction, Tyler supported children's metacognition and motivation for SR. The feedback could have helped children think about how to elaborate their ideas or how to adjust the structure of their arguments for the persuasive writing task.

At a table in the room, some children had gathered to work in a small group to finish their charts. That children were afforded the opportunity to discuss their learning and work collaboratively lent evidence to the presence of a community of leaners in Tyler's classroom. During the persuasive writing task, Tyler led a short discussion about what an opinion was and the ingredients of a piece of persuasive writing (e.g., introduction, topic sentence, and supporting arguments). Tyler asked children "What is a reason you like uniforms". A student responded by offering that "They would all be equal, and bullies would not be able to make fun of them". Tyler gave the student a positive evaluation by saying, "That is a good example because you gave a reason, and then supported it."

Tyler continued to provide support to children by urging them to write three paragraphs about their positions, and to use their charts as a support tool. Once children began to either finish their charts, or write their paragraphs, Tyler circulated the room to provide individual support to children as they worked on the task.

Noise levels in the room rose, and Tyler asked the class "Is this a good working environment right now?", to have the children evaluate the noise level. In response, the children commenced working again at a lower noise level. As Tyler continued around the room to support the children's learning, he noticed that a child was distracting his group members. 
Tyler approached the boy and told him that if he could not handle working in a group, he would have to work on his own.

Tyler moved to a child's desk to review her work and two more children waited in line to have their work evaluated. Once again, noise levels rose and children became distracted by objects in the classroom (e.g., throwing paper clips, breaking pencils). Tyler drew children's attention to the noise level again, and children were quiet. Moments later, children were asked to finish what they were working on and then they were asked to clean up.

Tori's reading task. I spent a full-day in Tori's grade 2/3 classroom during February 2015 and observed a total of three lessons. I decided to focus on one reading task to contrast the ways in which the features of instruction were observed in Tyler's grade 3/4 writing task. This comparison was thought to be appropriate as both activities had goals of developing children's language and literacy skills. Figure 2 displays the features of classroom instruction that were implemented during Tori's reading task. Tori's task was a read aloud task that children completed alongside peers. Only two of the eight features of instruction were observed during Tori's task, namely teacher and peer support but they were judged to be somewhat implemented in support of SR during the reading task.

The writing task Tori implemented was not judged to be a task that was complex by design. However, the task had potential to meet multiple goals to support children's reading comprehension, and to help them learn how to follow sentences during reading. To accomplish these goals more instrumental support from the teacher and more design and development of the task was needed than what was observed on this day. 
Tori introduced the reading task to students after lunch and told them they would be completing their weekly shared reading activity. Tori indicated that this activity was employed at the end of every week because she wanted children to have an opportunity to practice reading in a fun way. Tori distributed the poem children would be reading for the task. She explained to them that they were to review the poem and examine each word in the poem as they read (aloud) together. Tori said to children "I want you to look at the words and read, not just memorize". After reading the short poem, Tori instructed all the boys to stand in front of the class and re-read the poem. Tori read the poem with the boys, and then instructed the boys to read without her as a group. After the boys finished the reading task, Tori instructed the girls in her classroom to participate in the same sequence of events. After each round of reading, Tori praised the children (e.g., "Good work everyone, that was wonderful reading!"). She finished the lesson by allowing children to line up to receive a prize (e.g., suckers, jelly beans). During the task, there was no evidence indicating that children were given opportunities to make meaningful self-regulating choices (e.g., what to read) and to control challenge (e.g., whether to work independently, in partners, or in small groups) during the reading task. Further, during the lesson there was no evidence of the self-evaluation or non-threatening evaluation features of instructions. Instead, Tori provided feedback to children in the form of external rewards. During the reading task, there was the potential to create instrumental forms of teacher and peer support, but these needed further development than what was observed. There was the potential to support participation in a community of learners by allowing children to collaborate during the reading task, however, children were not given the opportunity to discuss their learning with peers or Tori. 
In sum, Tyler and Tori's classroom lessons differed in terms of the presence and implementation of the features of instruction and how they provided opportunities for children's SR. During Tyler's "uniform task", he employed eight features (complex tasks, choice, control over challenge, self-evaluation, teacher and peer support, non -threatening evaluations, and communities of learners). In particular, Tyler provided instrumental scaffolding for SR that supported their engagement in metacognition, motivation, and strategic action. Children in Tyler's classroom were observed taking up opportunities to engage in SR by incorporating Tyler's feedback to revise their work. Tori's "reading task" indicates that she did not employ six of the features of instruction linked to children's SR: complex tasks, choices, control over challenge, self-evaluation, non-threatening evaluations, and a community of learners. In Tori's classroom, children's opportunities for metacognition, motivation, and strategic action (SR) were limited. In these ways, the opportunities and support for children's SR in these classrooms differed.

\section{Discussion}

Consistent with previous research (Hutchinson, 2013; Perry \& Vandekamp, 2000), results of the present study revealed that SR was a significant predictor of academic achievement when controlling for the statistical effects of the demographic variable, sex. That is, children who were likely to communicate their emotions effectively and who were able to manage instructions to complete tasks independently were also likely to achieve academically.

Findings from the present study indicated that teachers provided higher ratings of SR to girls compared to boys. These findings align with previous research indicating that girls are perceived to be more self-regulating than boys, at least in the early elementary years of school 
(Diamond \& Lee, 2011; Hutchinson, 2013, Elliot- Faust \& Pressley, 1986; Perry, Thauberger, \& Hutchinson, 2010; Perry \& Vandekamp, 2000). This finding raises questions about why these differences are observed. In particular, research should focus on issues surrounding possible teacher or measurement bias when obtaining ratings of boys' and girls' SR (Hutchinson, 2013). Additionally, these findings raise questions about whether classrooms are ready to meet the unique learning needs of boys and the opportunities boys' need for developing SR.

The present study employed classroom observations to examine the extent to which eight features of instruction were implemented in literacy lessons from two classroom teachers. A limitation of implementing an observational measurement is the labor-intensive nature of this methodology. For this study the intensive process limited the sample, resulting in restricted generalizability of the present findings (Perry \& Vandekamp, 2000). Consistent with previous research (Hutchinson 2013;Perry, 1998; Perry \& Vandekamp, 2000) the current study found that the eight features of classroom contexts provided opportunities for children's SR and that there were qualitative differences in teachers' implementation of the features. These findings suggest that even if a teacher uses features of instruction in meaningful ways, they may not be implemented in ways that support SR across all lessons. Furthermore, teachers may implement the features more effectively in certain subjects (e.g., language, science; Perry, Phillips, \& Hutchinson, 2006).

The writing task in Tyler's classroom and the reading task in Tori's classroom were chosen to illustrate how the presence or absence and implementation of features of contexts can afford or constrain opportunities for SR. The observation in Tyler's class indicates how he implemented some of the features (complex tasks, choice, control over challenge, and teacher 
support) in ways that afforded opportunities for children's metacognition, motivation, and strategic action during the persuasive writing task. The observation in Tori's class indicates that she implemented a more limited set of features in her reading task and as a result children's opportunities for SR were constrained. The results of this study indicate that the tasks and supports afforded to children while learning were critical for supporting metacognition, motivation, and strategic action. For example, when Tyler supported children by first evaluating their work in a non-threatening manner followed by asking them to elaborate on their arguments. This non-threatening evaluation allowed for children to revisit their work, and motivated children to think about what strategies they could employ to better support their writing.

In closing, some of the limitations, directions for future research, and implications are discussed.

\section{Limitations}

A limitation of the current study was the small sample size, which inhibited the use of multi-level modeling, to examine the relationship between individual children's SR and classroom level features of instruction. Another limitation of this study is the recruitment of participating teachers. The two teachers in this study were self-selected and may have enrolled in the study based on their interest in promoting SR.

\section{Future Directions}

The findings presented above point to future work on SR in at least two areas. First longitudinal, multi-level research designs are needed to investigate how children's developing SR changes in relationship to features of classroom context during the elementary school years. 
Second, future research should involve mixed-method research designs to triangulate data from different sources and measure SR in classrooms. Gathering information from different sources is essential to creating a comprehensive understanding of how SR is presented in classrooms.

\section{Implications}

The recommendations for future work have implications for educators. Results of this study highlight the need to provide pre-service and in-service teachers with education that emphasizes the benefits of teaching towards SR in classrooms (Perry, Hutchinson, \& Thauberger, 2008). The qualitative data from this study provides descriptive information about the extent of implementation of the eight features of instruction, and how they provide children opportunities for SR classrooms.

This information may advocate that teachers' need to be supported to promote SR in classrooms. Specifically, teachers may benefit from one-on-one support from researchers (Thauberger, Hutchinson, \& Perry, 2007) or from their colleagues (Perry \& Vandekamp, 2000) to incorporate features of instruction into their lessons.

Finally, this research indicates that the eight features of classroom instruction can be employed to create a rich academic context that can serve to support children's development of and engagement in ER and SRL. The present study contributes to the literature by adding a contextual perspective to what transpires in classrooms, and how the eight features of instruction are related to elementary school children's SR. 


\section{References}

Barnes, K. J., Vogel, K. A., Beck, A. J., Schoenfeld, H. B., \& Owen, S. V. (2008). Self-r egulation strategies of children with emotional disturbance. Physical \& Occupational Therapy in Pediatrics, 28(4), 369-387. doi:10.1080/01942630802307127

Battistich, V., Solomon, D., Watson, M., \& Schaps, E. (1996). Caring school communities. Educational Psychologist, 32(3), 137-151.

Bodrova, E., Germeroth, C., \& Leong, D. J. (2013). Play and self-regulation: Lessons from vygotsky. American Journal of Play, 6(1), 111.

Brown, A. L., \& Campione, J. C. (1994). Guided discovery in a community of learners. In K. McGilly (Ed.), Classroom lessons: Integrating cognitive theory with classroom practice.(pp. 229-270). Cambridge, MA: MIT Press.

Butler, R. (1990). The effects of mastery and competitive conditions on self-assessment at different ages. Child Development, 61, 201-210.

Collins, A., Brown, J. S., \& Newman, S. E. (1989). Cognitive apprenticeship: Teaching the crafts of reading, writing, and mathematics. In L. B. Resnick (Ed.), Knowing, learning, and instruction: Essays in honor of Robert Glaser (pp. 453-494). Hillsdale, NJ: Lawrence Erlbaum Associates, Inc.

Corno, L. (2001). Volitional aspects of self-regulated learning. In B. J. Zimmerman \& D. H. Schunk (Eds.), Self-regulated learning and academic achievement: Theoretical perspectives (2 ed., pp. 191-225). Mahwah, NJ: Lawrence Erlbaum Associates Publishers. 
DeWall, C. N., Baumeister, R. F., Stillman, T. F., \& Gailliot, M. T. (2007). Violence restrained: Effects of self-regulation and its depletion on aggression. Journal of Experimental Social Psychology, 43(1), 62-76. doi:10.1016/j.jesp.2005.12.005

Diamond, A. \& Lee, K. (2011). Interventions shown to Aid Executive Function Development in Children 4-12 Years Old. Science, 333, 959-964.

Eisenberg, N., Fabes, R., Murphy, B., Maszk, P., Smith, M., \& Karbon, M. (1995). The Role of Emotionality and Regulation in Childrens Social Functioning - A Longitudinal-Study. Child Development, 66(5), 1360-1384.

Eisenberg, N., \& Spinrad, T. L. (2004). Emotion-related regulation: Sharpening the definition. Child Development, 75(2), 334-339. doi:10.1111/j.1467-8624.2004.00674.x

Eisenberg, N., \& Sulik, M. J. (2012). Emotion-related self-regulation in children. Teaching of Psychology, 39(1), 77-83. doi:10.1177/0098628311430172

Elliot-Faust, D., \& Pressley, M. (1986). How to teach comparison processing to increase children's short- and long-term listening comprehension monitoring. Journal of Educational Psychology, 78(1), 27-33. Retrieved from http://search.proquest.com/docview/63316147?accountid=15115

Fuhs, M. W., Nesbitt, K. T., Farran, D. C., \& Dong, N. (2014). Longitudinal associations between executive functioning and academic skills across content areas. Developmental Psychology, 50(6), 1698. Retrieved from http://search.proquest.com/docview/1535388685?accountid=15115

Heyman, G. D., \& Dweck, C. S. (1998). Children's thinking about traits: Implications for judgments of the self and others. Child Development, 69(2), 391. doi:10.2307/1132173 
Hutchinson, L. R. (2013). Young Children's Engagement in Self-Regulation at School (Doctoral dissertation). Retrieved from https://circle.ubc.ca/bitstream/.../ubc_2013_fall_hutchinson_lynda.pdf?

Hutchinson, L. R. \& Perry, N. E.,(2014) Development and Validation of the SRISI. Manuscript submitted for publication.

Konold, T. R., \& Pianta, R. C. (2005). Empirically-derived, person-oriented patterns of school readiness in typically-developing children: Description and prediction to first-grade achievement. Applied Developmental Science, 9, 174-187.

Martin, A., Ginns, P., Brackett, M., Malmberg, L., Hall, J. (2013). Academic buoyancy and psychological risk: Exploring reciprocal relationships. Learning and Individual Differences, 27, 128-133.

McCaslin, M. (2009). Co-regulation of student motivation and emergent identity. Educational Psychologist, 44(2), 137-146. doi:10.1080/00461520902832384

Merritt, E. G., Wanless, S. B., Rimm-Kaufman, S. E., Cameron, C., \& Peugh, J. L. (2012). The contributions of teachers' emotional support to children's social behaviors and selfregulatory skills in first grade. School Psychology Review, 41(2), 141.

Paris, S., Paris, A. (2001). Classroom Applications of Research on Self-Regulated Learning. Educational Psychologist. 36 (2), 89-101.

Perry, N. E. (1998). Young children's self-regulated learning and contexts that support it. Journal of Educational Psychology, 90, 715-729.

Perry, N. E., Phillips, L., \& Hutchinson. (2006). Mentoring student teachers to support selfregulated learning. Elementary School Journal, 106, 237-254 
Perry, N. E., Thauberger, C., \& Hutchinson, L. R., (2010). gStudy traces of children's selfregulated learning in the Lifecycles Learning Kit. Psychological Test and Assessment Modeling, 52, 432-453.

Perry, N. E., Turner, J. C., \& Meyer, D. K. (2006). Classrooms as contexts for motivating learning. In P. Alexander \& P. H. Winne (Eds.),Handbook of Educational Psychology (2nd Ed., pp. 327-490). APA/MacMillan.

Perry, N. E., \& Winne, P. H. (2006). Learning from learning kits: GStudy traces of students' selfregulated engagements with computerized content. Educational Psychology Review, 18(3), 211-228. doi:10.1007/s10648-006-9014-3

Perry, N. E., \& Winne, P.H. (2013). Keys to Supporting Slef-Regulated Learning. Teacher News Magazine, 25(5), n.a. Retrieved from http://bctf.ca/publications/NewsmagArticle.aspx?id=29340

Perry, N. E., \& VandeKamp, K. J. (2000). Creating classroom contexts that support young children's development of self-regulated learning. International Journal of Educational Research, 33(7), 821-843. doi:10.1016/S0883-0355(00)00052-5

Rudasill, K. M., \& Rimm-Kaufman, S. E. (2009). Teacher-child relationship quality: The roles of child temperament and teacher-child interactions. Early Childhood Research Quarterly, 24(2), 107-120. doi:10.1016/j.ecresq.2008.12.003

Samarapungavan, A., Mantzicopoulos, P., \& Patrick, H. (2008). Learning science through Inquiry in kindergarten. Science Education, 92(5), 868-908. doi:10.1002/sce.20275

Sokol, B. W., Grouzet, F. M. E., \& Mueller, U. (2013). Self-regulation and autonomy: Social and developmental dimensions of human conduct. New York: Cambridge University Press. 
Stefanou, C., Perencevich, K., DiCinto, M., \& Turner, J. (2004). Supporting autonomy in the classroom: Ways teachers encourage student decision making and ownership. Educational Psychologist, 39(2), 97-110.

Strauss, A. C., \& Corbin, J. (Eds.). (1997). Grounded theory in practice. Thousand Oaks, CA: Sage Publications.

Surman, C. B. H., Biederman, J., Spencer, T., Yorks, D., Miller, C. A., Petty, C. R., \& Faraone, S. V., (2011). Deficient emotional self-regulation and adult attention deficit hyperactivity disorder: A family risk analysis. The American Journal of Psychiatry, 168(6), 617-23. Retrieved from http://search.proquest.com/docview/890044474?accountid=15115

Thauberger, C., Hutchinson, L., \& Perry, N. (2007). Mentoring student teachers to design and implement literacy tasks that support self-regulated reading and writing. Reading \& Writing Quarterly, 23(1), 27-50. doi:10.1080/10573560600837636

Thomas, R.M. (2005). Comparing theories of child development (5th ed.). Belmont, CA: Wadsworth.

Turner, J., \& Paris, S. G. (1995). How literacy tasks influence children's motivation for literacy. The Reading Teacher. 48(8), 662-673

Vandenberg, R. J., \& Lance, C. E. (2000). A review and synthesis of the measurement invariance literature: Suggestions, practices, and recommendations for organizational research. Organizational Research Methods, 3, 4-69

Wade, C., Tavris, C., Saucier, D. M., \& Elias, L. J. (2014). Psychology. Toronto: Pearson. 
Winne, P. H., \& Perry, N. E. (2000). Measuring self-regulated learning. In M. Boekarts, P. Pintrich, \& M. Zeidner (Eds.), Handbook of self-regulation (pp. 532-566). Orlando, FL: Academic Press.

Zimmerman, B. J. (1990). Self-Regulated Learning and Academic Achievement: An Overview. Educational Psychologist, 25(1), 3.

Zimmerman, B. J., \& Pons, M. M. (1986). Development of a structured interview for assessing student use of self-regulated learning strategies. American Educational Research Journal, 23(4), 614-628. doi:10.2307/1163093

Zimmerman, B. J., \& Schunk, D. H. (2011). Handbook of self-regulation of learning and performance. New York, NY: Routledge. 
Table 1

Demographic Information from Participating Classrooms

\begin{tabular}{ccccccc}
\hline $\begin{array}{c}\text { Classroom } \\
\text { Teacher }\end{array}$ & \multicolumn{2}{c}{ Number of Students } & & SES & $\begin{array}{c}\text { Number of } \\
\text { Visible } \\
\text { Minority }\end{array}$ & $\begin{array}{c}\text { ESL } \\
\text { Students }\end{array}$ \\
& Boys & Girls & Total & & & \\
\hline Tyler & 11 & 9 & 20 & Low-Middle & 5 & 1 \\
Tori & 10 & 9 & 19 & Low-Middle & 1 & 0 \\
\hline
\end{tabular}

Table 2

Descriptive Statistics for the SR and Academic Achievement Variables

\begin{tabular}{lcccccc}
\hline $\begin{array}{c}\text { Classroom } \\
\text { Teacher }\end{array}$ & \multicolumn{3}{c}{ Self-Regulation } & & & Achievement \\
& M (SD) & Min & Max & M (SD) & Min & Max \\
\hline Total Sample & $4.47(1.42)$ & 1.50 & 6.63 & $4.48(1.44)$ & 2 & 7 \\
\hline Tyler & $4.40(1.26)$ & 1.75 & 6.13 & $4.65(1.32)$ & 2 & 7 \\
Tori & $4.53(1.61)$ & 1.50 & 6.63 & $4.31(1.58)$ & 2 & 6 \\
\hline
\end{tabular}

Table 3

Multiple Regression Analysis of SR Predicting Academic Achievement when Controlling for Sex $(N=33)$

\begin{tabular}{lcccc}
\hline Model & $\begin{array}{c}\text { Unstandardized } \\
B\end{array}$ & $\begin{array}{c}\text { Standardized } \\
\text { beta }\end{array}$ & $t$ & $p$ \\
\hline Sex & -.26 & -.09 & -.52 & .608 \\
SR & .64 & .63 & 3.61 & .001 \\
\hline
\end{tabular}


Table 4

Features of Instruction and Opportunities for SR in Classrooms

\begin{tabular}{|c|c|c|c|c|c|c|c|c|c|}
\hline Teacher & Topic & $\begin{array}{c}\text { Complex } \\
\text { task }\end{array}$ & Choice & $\begin{array}{c}\text { Control } \\
\text { over } \\
\text { Challenge }\end{array}$ & $\begin{array}{c}\text { Self- } \\
\text { Evaluation }\end{array}$ & $\begin{array}{l}\text { Teacher } \\
\text { Support }\end{array}$ & $\begin{array}{c}\text { Peer } \\
\text { Support }\end{array}$ & $\begin{array}{c}\text { Non- } \\
\text { Threatening } \\
\text { Evaluations }\end{array}$ & $\begin{array}{l}\text { Community } \\
\text { of Learners }\end{array}$ \\
\hline Tyler & Language & $\checkmark$ & $\checkmark$ & $\checkmark$ & & $\checkmark$ & $\checkmark$ & & $\checkmark$ \\
\hline Tyler & Language & $\checkmark$ & $\checkmark$ & $\checkmark$ & $\checkmark$ & $\checkmark$ & $\checkmark$ & $\checkmark$ & $\checkmark$ \\
\hline Tyler & Math & $\checkmark$ & $\checkmark$ & & $\checkmark$ & $\checkmark$ & $\checkmark$ & $\checkmark$ & $\checkmark$ \\
\hline Tori & Math & & & & & $\checkmark$ & $\checkmark$ & & \\
\hline Tori & Centers & & $\checkmark$ & $\checkmark$ & & $\checkmark$ & $\checkmark$ & & \\
\hline Tori & Language & & & & & $\checkmark$ & $\checkmark$ & & \\
\hline
\end{tabular}

Note: Grey shading represents fully implemented during the lesson, green = somewhat implemented, and pink represents not implemented. 


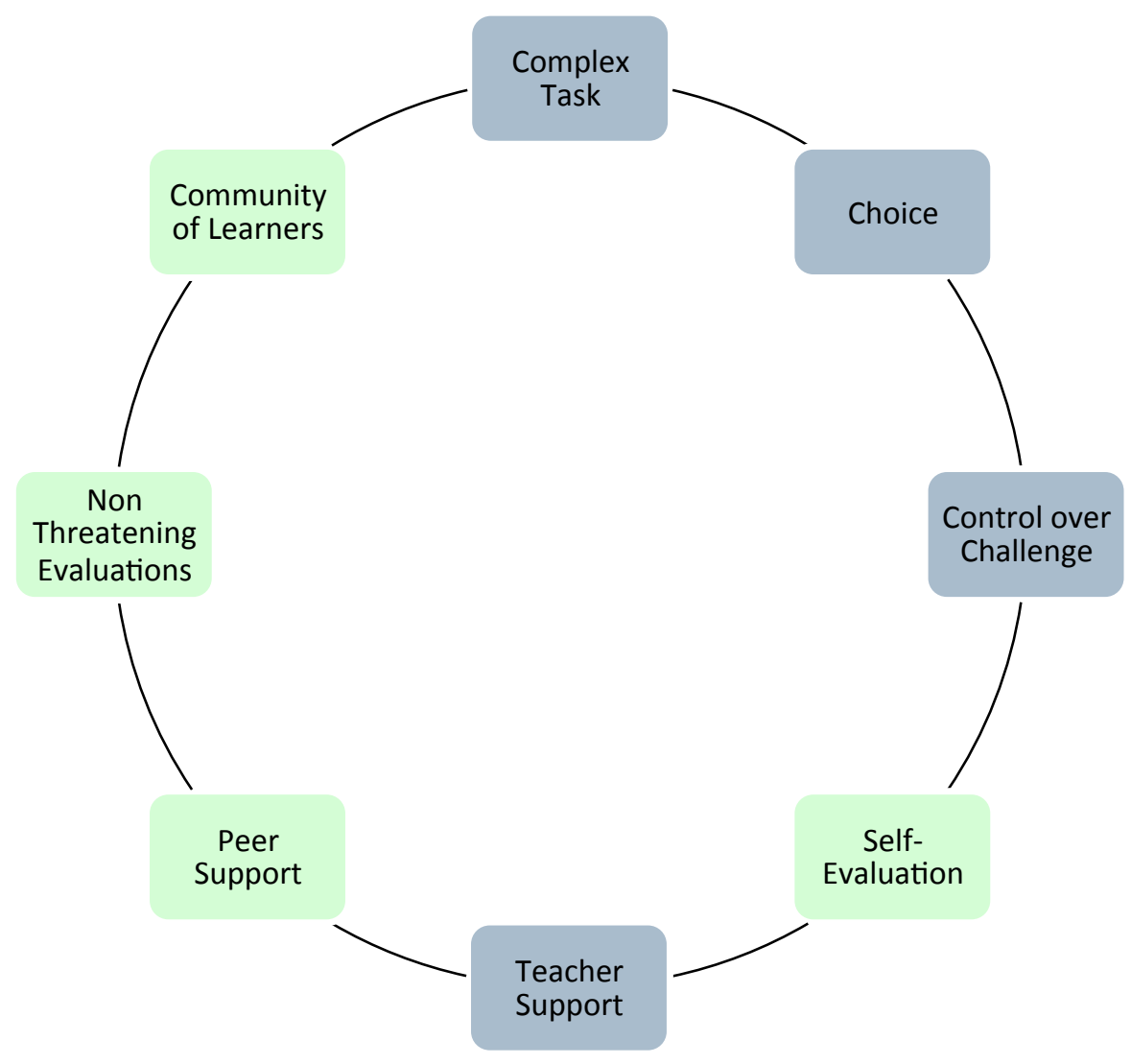

Legend

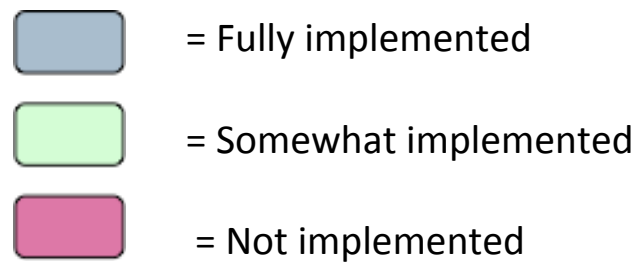

Figure 1. The features of instruction Tyler implemented to support ER and SRL during the persuasive writing task. 


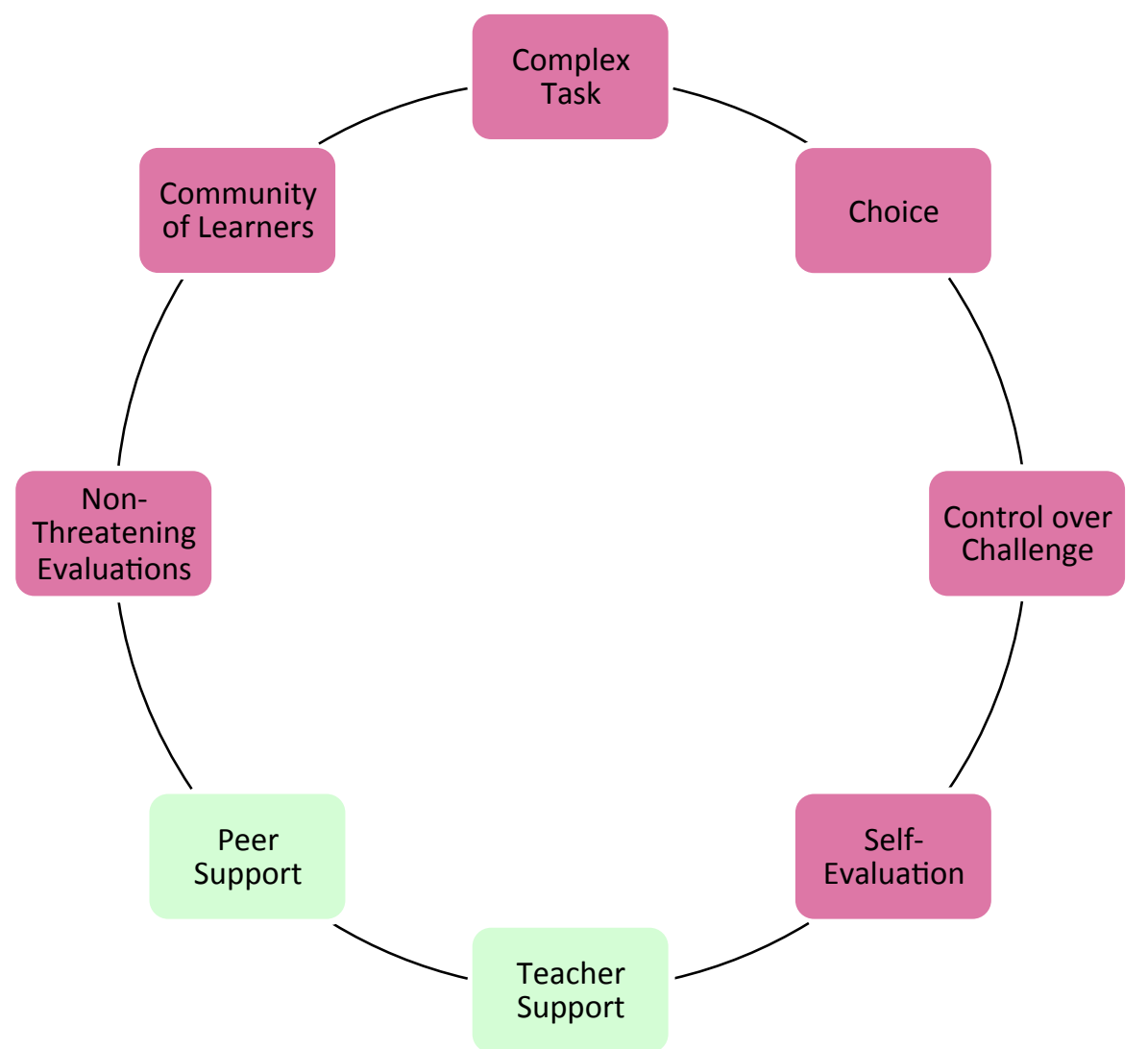

Legend

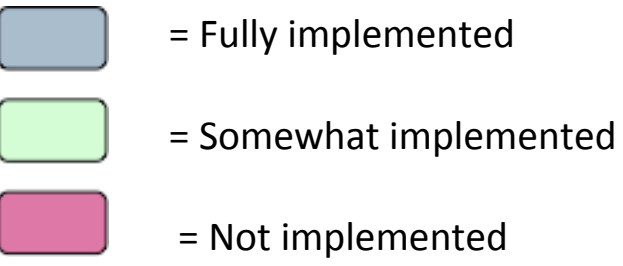

Figure 2. The features of instruction Tori implemented to support SR during the reading task. 
Appendix A

Self-Regulation in School Inventory (C) (Hutchinson \& Perry, 2014)

1. Overall, what is the child's achievement level in terms of provincial expectations?

2. Makes realistic evaluations of his/her performance on a task.

3. Offers to refer a peer to information/books that assist that peer with a project or task.

4. Enjoys and/or values learning new things.

5. Recognizes how much support peers need for learning.

6. Is able to talk about feelings or describe emotions.

7. Offers instrumental support to peers who are struggling with academic tasks (e.g., takes on another peer's classroom responsibilities when that peer needs more time to catch up on academic tasks).

8. Understands what is required to "meet expectations" for academic tasks.

9. Engages in positive self-talk or other productive strategies when faced with challenging or upsetting situations, rather than letting negative emotions get in the way. 
Appendix B

Classroom Observation Instrument

(Adapted From Perry, 1998; Perry, VandeKamp, Mercer, \& Nordby (C 2000)

ID

Teacher

Observer

Grade Time Start

Date Time Stop

School Time Total

Description: 
Examples of Classrooms Supporting Young Children's Engagement in ER, SRL, and SRSR

\begin{tabular}{|c|c|}
\hline Category & Examples \\
\hline Complex Tasks & $\begin{array}{l}\text { The teacher creates meaningful tasks/ activities (e.g., class discussion time on writing outlines, } \\
\text { how to effectively brain storm/creating concept maps, guidelines for creating writing } \\
\text { summaries) that provide opportunities for children to attain multiple learning goals (e.g., goals } \\
\text { to develop skills of how to construct a writing outline, to engage in creative writing, to learn } \\
\text { how to work with other students in the classroom). } \\
\text { The teacher provides tasks/activities (e.g., supporting all students to keep a personal science } \\
\text { log with terminology, diagrams, things children have learned during the unit) that presents } \\
\text { students with opportunities to employ skills from across subjects (e.g., writing, art, science) to } \\
\text { support learning. } \\
\text { The teacher creates tasks/activities (e.g., shared reading activities, experiments) that provide } \\
\text { opportunities for children to engage in a number of processes and support children's learning } \\
\text { (e.g., predicting, analyzing, reasoning, remembering). } \\
\text { Classroom activities and tasks (e.g., creating math problems based on children's understanding } \\
\text { of probability) provide opportunities for children to showcase their learning in different ways } \\
\text { (e.g., pictures, writing, building a game). }\end{array}$ \\
\hline Choice & $\begin{array}{l}\text { Children have choices about who they can work with. } \\
\text { Children have choices about where to work (e.g., library, hall, or to another area to work } \\
\text { quietly - free of distractions). } \\
\text { Children make decisions about when they work on tasks and activities (e.g., students prioritize } \\
\text { when they will work on reading, writing, math). } \\
\text { Children decide what they will work on during a class time (e.g., writing or science or a bit of } \\
\text { both). }\end{array}$ \\
\hline $\begin{array}{c}\text { Control Over } \\
\text { Challenge }\end{array}$ & $\begin{array}{l}\text { Children suggest two of their favorite topics (e.g., polar bears, the ocean) as ideas for a group } \\
\text { project. } \\
\text { Children are supported to ask for guidance for learning from a teacher or peer. } \\
\text { Children are supported to use resources (e.g., books, internet) when they are having } \\
\text { difficulties finding information about topics they are researching. } \\
\text { Children are supported to negotiate with others when they have disagreements about a task } \\
\text { or project they are working on with other children. }\end{array}$ \\
\hline $\begin{array}{c}\text { Student } \\
\text { Self-Evaluation }\end{array}$ & $\begin{array}{l}\text { Children have a large discussion with the class about what they have learned. } \\
\text { Children have conferences with the teacher about their learning progress on a science project. } \\
\text { Students use rubrics or checklists to evaluate their learning (e.g., evaluation criteria set by the } \\
\text { class). } \\
\text { Students keep journals about what they have learned in a subject using notebooks they review } \\
\text { with the teacher. }\end{array}$ \\
\hline Teacher Support & Teachers provide hints when work is difficult (e.g., what could you do if you can't spell a \\
\hline
\end{tabular}




\begin{tabular}{|c|c|}
\hline Category & Examples \\
\hline & $\begin{array}{l}\text { word?). } \\
\text { Teachers model strategies for cooperating with others (e.g., how would you ask Julia if you } \\
\text { wanted to borrow her pencils? What could you say if you have another idea for the group } \\
\text { project?). } \\
\text { Teachers model thinking strategies so students can work independently (e.g., If I get stuck } \\
\text { spelling a word in my head, what strategy could I use to help me figure out how to spell it?"). } \\
\text { Teachers anticipate students' needs by scaffolding positive conflict resolution prior to task } \\
\text { engagement (e.g., What are some things we can do we do if there is a disagreement between } \\
\text { classmates?). }\end{array}$ \\
\hline Peer Support & $\begin{array}{l}\text { Peers show other children how they have solved a task. } \\
\text { Peers ask other children to work collaboratively. } \\
\text { Peers volunteer information that can help another child with her/his project. } \\
\text { Peers remind classmates to stay on task while working together. }\end{array}$ \\
\hline $\begin{array}{c}\text { Non- } \\
\text { Threatening/Non- } \\
\text { Competitive } \\
\text { Evaluations }\end{array}$ & $\begin{array}{l}\text { Teachers support children to focus on their personal learning progress (rather than comparing } \\
\text { him/herself to peers). } \\
\text { Teachers encourage children to view feedback as opportunities for them to improve their } \\
\text { learning (rather than as competition). } \\
\text { Teachers provide children with support that allows them to learn how to give constructive } \\
\text { feedback to other children so that they help each other accomplish learning. }\end{array}$ \\
\hline $\begin{array}{l}\text { Communities Of } \\
\text { Learners }\end{array}$ & $\begin{array}{l}\text { Teachers and children meet to discuss progress on individual tasks (e.g., what's involved, what } \\
\text { materials are needed, who to ask for expertise). } \\
\text { Teachers lead a large discussion so that all children have opportunities to share their ideas and } \\
\text { strategies for learning with other classmates. } \\
\text { Teachers provide children with support (e.g., strategies student can use to help themselves } \\
\text { make their learning more interesting based on their interests) that is tailored to an individual } \\
\text { child's needs for learning, emotional support/warmth, and guidance. } \\
\text { Individual children are supported by their classmates and teachers when they recognize they } \\
\text { need help from someone else to complete work. }\end{array}$ \\
\hline
\end{tabular}




\section{Observation Checklist for Examining Features of Classroom Contexts}

Directions: When analyzing a lesson for the each of the categories/features of contexts (e.g., Choice, Control Over Challenge etc) please indicate (with a checkmark) whether a category is (a) present, and (b) supports self-regulation.

ID:

Lesson Type:

Date:

\begin{tabular}{|l|l|l|l|l|l|}
\hline Category & Present & \multicolumn{2}{c|}{ Implementation to Support Self-Regulation } \\
\hline & No & Yes & $\begin{array}{c}\text { Not } \\
\text { Implemented }\end{array}$ & $\begin{array}{c}\text { Somewhat Implemented } \\
\text { Implemented }\end{array}$ & \\
\hline Complex Tasks & & & & & \\
\hline Choices & & & & & \\
\hline Control Over Challenge & & & & & \\
\hline Student Self-Evaluation & & & & & \\
\hline Teacher Support & & & & & \\
\hline Peer Support & & & & & \\
\hline Non-Threatening Evaluations & & & & & \\
\hline Communities Of Learners & & & & & \\
\hline
\end{tabular}


Appendix C

Classroom Demographic Form (Hutchinson, 2013)

Classroom Teacher ID:

Classroom SES Rating (choose one):

Low Middle-Low Middle Middle-High High

Number of children in the class:

Number of boys:

Number of girls:

Number of children from visible minority backgrounds (children who are not Caucasian):

Number of children who speak English as a second language:

Special Education Designation: 